\title{
Poster: A Scoping Review of Alternative Credit Scoring Literature
}

\author{
Rebecca, W, Njuguna* \\ Department of Information Systems, University of Cape \\ Town \\ njgreb001@myuct.ac.za
}

\author{
Karen, Sowon \\ Department of Information Systems, University of Cape \\ Town \\ kc.sowon@uct.ac.za
}

\begin{abstract}
This paper covers a scoping review to establish the breadth of alternative credit scoring literature. The field is nascent and gaining popularity due to the crucial role alternative data is playing to accelerate financial inclusion. Historically, evaluating creditworthiness required availability of past financial activity such as loan repayment. Such stringent requirements rendered people with little or no financial history 'credit invisible'. Advancements in Artificial Intelligence and Machine Learning have enabled scoring algorithms to work with non-financial data such as digital footprints from mobile devices and psychometric data to compute credit scores. Although the largest portion of 'credit invisibles' are in developing economies, research in the area is predominantly originating from developed economies and most alternative credit scoring models are trained with data from developed economies. There is need for more research from developing contexts and utilization of alternative data from populations with a smaller digital footprint.
\end{abstract}

\section{CCS CONCEPTS}

- Applied computing $\rightarrow$ Law, social and behavioral sciences; Economics.

\section{KEYWORDS}

Alternative credit scoring, Credit invisibles, Alternative data

\section{ACM Reference Format:}

Rebecca, W, Njuguna* and Karen, Sowon. 2021. Poster: A Scoping Review of Alternative Credit Scoring Literature. In ACM SIGCAS Conference on Computing and Sustainable Societies (COMPASS) (COMPASS '21), June 28July 02, 2021, Virtual Event, Australia. ACM, New York, NY, USA, 8 pages. https://doi.org/10.1145/3460112.3471972

\section{INTRODUCTION}

Credit plays a central role in the lives of individuals and economies in both developed and developing contexts [17]. However, access to credit is starkly uneven. Globally, 1.7 billion adults are still unbanked, having no access to any form of financial services including credit [11]. Financial inclusion, which is measured by bank or mobile money account ownership, is relatively high in developed economies. The unbanked billions virtually constitute of adults from developing economies, of which women and members of poorer

Permission to make digital or hard copies of part or all of this work for personal or classroom use is granted without fee provided that copies are not made or distributed for profit or commercial advantage and that copies bear this notice and the full citation on the first page. Copyrights for third-party components of this work must be honored For all other uses, contact the owner/author(s).

COMPASS '21, June 28-7uly 02, 2021, Virtual Event, Australia

(c) 2021 Copyright held by the owner/author(s).

ACM ISBN 978-1-4503-8453-7/21/06.

https://doi.org/10.1145/3460112.3471972 households are overrepresented [11]. Spotlight has been shone on credit as a potent means to fight poverty by enabling socioeconomic empowerment [17]. The Nobel Laureate Muhammad Yunus has even argued that access to credit should be considered a human right [17].

Historically, who gets credit and who doesn't has rested on classifications of citizens. Credit scoring is a way of classifying individuals to determine their likelihood to default on a loan [2,27]. The practice dates back to the 1960s when the proliferation of credit cards in the United States led issuers to find more effective and efficient ways of predicting creditworthiness [41]. Assessments for creditworthiness were made from observations of borrowers' repayment behaviour on previous loans [27, 41]. The assumption was that past data could generate predictions about the borrower's future behaviour [27]. There were still biases due to the role of loan officers in the credit risk assessment process. Fair, Isaac and Company (FICO) score was developed in 1989 with the goal of eliminating such prejudices from the process [32]. The FICO score utilises factors such as repayment history, loan amounts and credit mix to calculate a consumer's credit score [32]. Credit scores were initially used for credit card risk assessment but later extended to personal loans, mortgage, and small business loans [41]. Use of credit scores has extended beyond banking to areas such as rental property and employment assessment, auto and home insurance and application for utility accounts [7, 37].

Due to the dependence on financial history to compute the initial credit score, some populations were left out of credit scoring who either had very little financial history or none [37]. Individuals with too little financial history or thin files are often referred to as 'credit unscored' and those without any financial history are referred to as 'credit invisible' [7, 37]. Advancements in technology, particularly Big Data and Machine Learning have brought about changes in credit scoring, by making it possible to analyse forms of data that were not traditionally used in credit scoring algorithms [27]. Some of the new data include how long one has lived in a particular address or held a certain job, age, income and age [12]. Use of such data alongside traditional financial data to enhance credit scoring is what constitutes Alternative Credit Scoring [12, 34]. While using non-traditional data to augment credit bureau data has been helpful for the 'unscored', it has not done much for the 'credit invisible' [31]. In developing countries where financial inclusion is low, there are many people, particularly the rural poor and women, who are 'credit invisibles' [28]. It is common in those contexts to depend on credit from informal sources, family and friends, and hence these transactions are invisible from credit scorers [15].

Extending credit to 'credit invisibles' has necessitated innovation on how to train credit scoring models to use non-traditional data to make reliable predictions on people's creditworthiness. There 
are currently many initiatives for financial inclusion in developing countries targeting 'credit invisibles' from governments, nongovernmental development agencies and profit-making Financial Technology (FinTech) companies [38]. Alternative credit scoring is being utilised in some of these initiatives [15]. As a starting point for an empirical study in a developing country, this paper seeks to map out available literature on alternative credit scoring. The aim of this scoping review is to explore the extent to which alternative credit scoring has been studied. Subsequently we desire to extract the methods that have been popularised so far in literature, and to reflect on the limitations and opportunities that these existing methods offer to developing countries. This paper is therefore guided by the following questions:

1. What type of data has been used for alternative credit scoring?

2. What key findings and concerns have been associated with the use of alternative data?

The rest of the papers is organised as follows: First, we expound the methodological steps followed to execute the scoping review. Key findings from the literature reviewed are then summarised, and finally the conclusion is drawn which includes recommendations for future research based on identified gaps.

\section{SCOPING REVIEW METHODOLOGY}

Owing to the nascency of the field in light of alternative scoring data, this study adopted a scoping review. Scoping reviews are specifically appropriate as a type of literature search and examination conducted when the aim is to gain an overview of a broad area [3]. One of the purposes for conducting scoping reviews, which is the motivation for this article, is to examine how research on a given topic has been conducted as well as identify knowledge gaps [3].

Like systematic literature reviews, scoping reviews follow systematic literature review principles that are informed by a priori protocol to ensure that the literature search is exhaustive, transparent and replicable [3]. The systematic protocol is detailed in the subsequent sections.

\subsection{Inclusion/Exclusion Criteria}

Eligible material entailed peer-reviewed literature, published in English and which addressed the concept of alternative credit scoring. We did not apply any year restriction to the search results to track the emergence of the concept of alternative credit scoring which is relatively nascent in literature following various recent technological developments including mobile technologies, Artificial Intelligence and Big Data.

Following screening and guided by the definition of alternative credit scoring that was adopted in this study, we excluded articles that did not specifically address use of non-traditional data for alternative credit scoring.

\section{$2.2 \quad$ Search strategy}

We sourced literature from the following databases that were considered relevant for their likely coverage of financial and IS-related literature: Scopus, Web of Science, ProQuest, EBSCOhost, ScienceDirect, IEEE Xplore, JSTOR and AIS eLibrary
The phrase "alternative credit scoring" was used on the various databases to retrieve literature. On all other databases except Science Direct, JSTOR and AIS eLibrary which do not allow the use of wild cards, the search phrase used was "alternative credit scor" in order to capture papers that either had 'alternative credit scoring' and/or 'alternative credit score'. The search phrase was enclosed in inverted commas to limit the results to only articles that had the specific phrase 'alternative credit scoring' and/or 'alternative credit score'. The decision to limit to the exact phrase was based on the pilot search that indicated that a broader search returned far too many irrelevant studies that had 'alternative' and 'credit scoring' in the text even though the studies had little to do with the alternative credit scoring concept. The broader searches returned thousands of results which would not be feasible to filter. Table 1 shows a summary of the search protocol and the number of hits per database.

\subsection{Screening Process}

The primary author applied the search phrase to databases, imported results to an Excel workbook, removed duplicates and screened for inclusion based on title and abstract. To determine final inclusion, two authors independently reviewed the full text. The first author reviewed for coverage of alternative credit scoring while the second author analysed the text to retrieve the selected synthesis dimensions that had been agreed upon a priori guided by the research questions. Discrepancies were resolved through discussion between the two authors. We also did backward searches from the articles screened. This iterative process added 14 articles to the list. The screening process is summarized in Figure 1. It is important to note that the search process is iterative and even though the results from backward search are represented at the top of the hierarchy for diagrammatic purposes, the backward search results were obtained during the assessment and analysis phases but each was subjected to the same screening process as the rest before being included for final analysis.

\subsection{Charting}

Once the final list of articles was agreed upon, the files were uploaded to NVivo for analysis. Coding was done on two themes that corresponded to the research questions. These themes were the types of alternative data and key findings and concerns of alternative data use. A separate analysis was done on Excel to map out descriptive statistics of the articles. The following details were charted for each article where applicable:

- Author(s) and year of publication

- Title

- Study setting i.e., location of empirical study or country of author(s)'s affiliated institution

- The type of study (conceptual or empirical)

- Study population

- Methodology

Results from the charting process are presented in Appendix I and the results from thematic analysis are presented in the next section. 
Table 1: Search protocol and hits summary

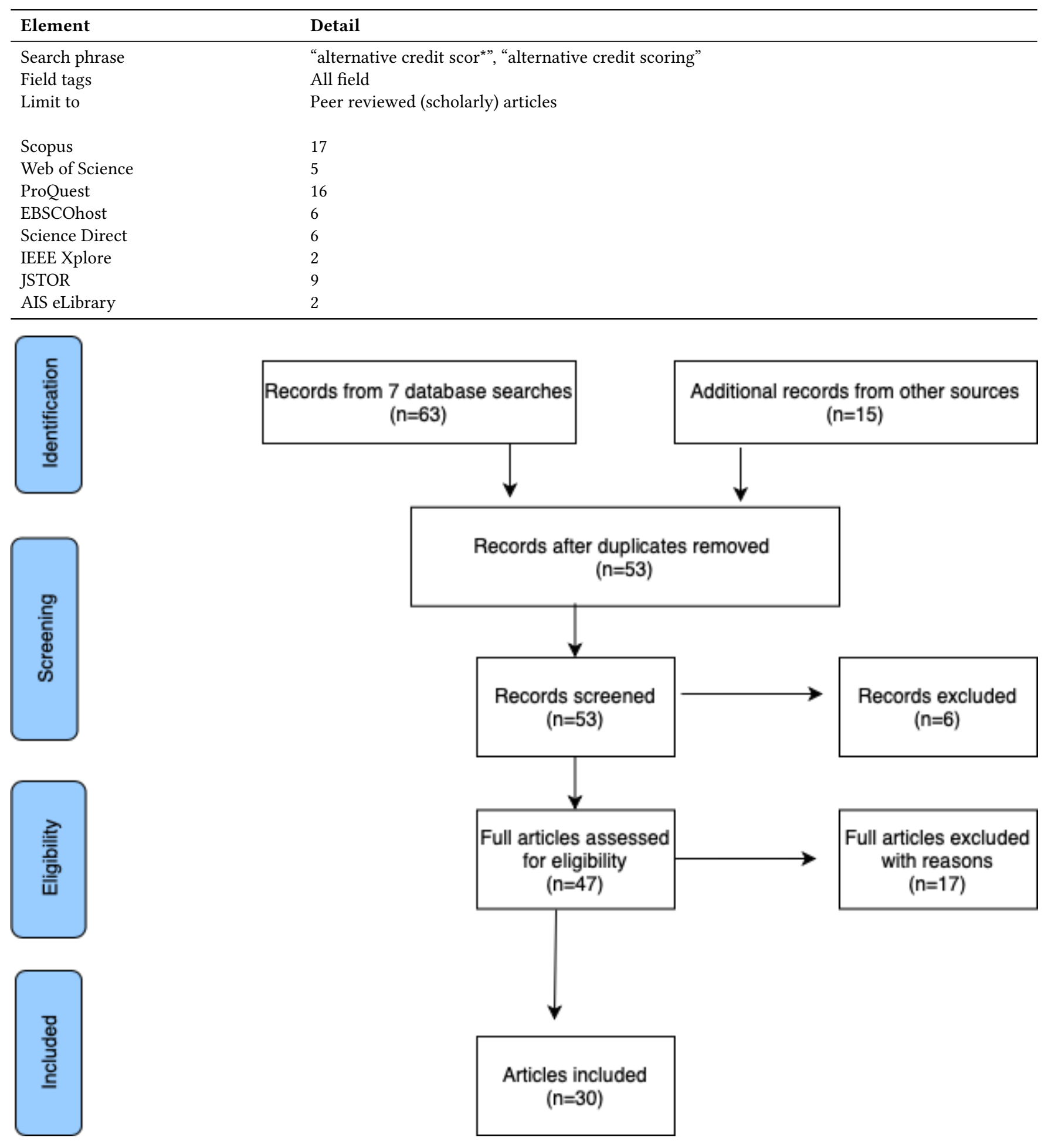

Figure 1: Scoping Review PRISMA Flow Diagram. 


\section{RESULTS SYNTHESIS}

All except two of the articles [9,25] retained based on the inclusion/exclusion criteria were published between 2016 and 2021. This supports the claim that alternative credit scoring focusing on nontraditional data points is a nascent field of study. Majority of the studies $(58.1 \%, \mathrm{n}=18)$ were empirical, $29 \%(\mathrm{n}=9)$ were conceptual while the rest were book reviews and reports. The dominant methodology was use of case studies, with more than a third of the studies featuring quantitative, qualitative and ethnographic case studies. Other methodologies featured were quantitative multivariate analysis, predictive modelling and mixed methods. In terms of geographical representation, eight studies originated from the United States which was the highest number from a single country, with only China and the United Kingdom following with two studies each. By region, Asia had the highest number of countries represented with seven countries. Europe had six, Sub-Saharan Africa had two and South America had only one.

\subsection{Types of alternative data}

While traditional credit scoring examined past financial behaviour to predict future financial behaviour, alternative credit scoring uses non-financial data to predict financial behaviour and creditworthiness [27]. Water, electricity, phone, cable and other utility bills are among the earliest non-traditional data to be incorporated into credit scoring $[1,7,16,18,20,27,31,37]$. Rental and utility data are considered more 'credit like' because they are able to offer insights over a long period and involve a significant proportion of an individual's income $[1,12,37]$. Local public records such as delinquency, traffic violations, bankruptcy, legal proceedings and disputes, evictions, criminal history, employment, immigration status, asset ownership and remittances have also been tapped into for credit scoring $[1,7,12,13,32,37]$. Credit scores are in a sense measures of stability. Therefore, rental and utility records that indicate that someone has lived in the same address for a number of years would be considered a good indicator of creditworthiness. Conversely, residential itinerancy and records of delinquency are considered behavioural indicators of credit risk [1,32].

Globally, more people have access to mobile phones than to bank accounts. $83 \%$ adults in developing countries have a mobile phone [23]. However, smartphone ownership is much lower, estimated at $45 \%$, compared to a global median of $76 \%$ [35]. Even among 'credit invisibles', mobile device ownership is high and the mobile devices generates a rich dataset from all the calls and text messages exchanged daily $[1,28,34]$. Mobile devices have a lot of other data points including the device model and manufacturer, applications installed among others $[18,33]$. That means that even individuals who have no bank accounts but have mobile phones generate a digital footprint that alternative credit scoring can derive risk assessment indicators from $[1,34]$. In contexts where mobile money is popular, additional data points from mobile phones include amounts sent and withdrawn, frequency of transactions and patterns of active days [33]. Digital footprints extend beyond call and text messages to social media activities, gaming, online shopping and geolocation data [20, 24, 27, 33, 38]. Mobile phone behaviour such as calls and texts made each day, frequency of airtime top-up and internet usage has been found to be a rich proxy for an individual's behaviour and lifestyle choices $[1,6,22,28,33,34]$. Some of the data collected from social media include the frequency of posting, use of photos and videos in posts, and what one 'likes' and comments on $[34,38]$. Further insights are derived from online relationships. Online friendships with creditworthy people is a good thing while connections with defaulters is a signal of bad credit quality [28, 33].

Psychometric data has also become popular for credit scoring $[1,8,12,24,27]$. Psychometrics are classically used for mental, behavioural and cognitive assessments. The premise for their use in credit scoring has been that the results can indicate some personality attributes which can predict an individual's willingness to pay debts $[1,12]$. Other claims include giving lenders an indication of an individual's character and self-control in spending and budgeting matters [8]. Academic records such as which college one attended, its national ranking and academic transcripts have also been utilised, with claims that there are patterns among alumni that link back to the institutions they attended [1,32]. Details such as how one uses capitalisation is considered useful. For instance, "typing in all caps is a red flag" (Rodriguez, 2020, p.1859). Even seemingly innocuous online behaviour such as how fast one scrolls through terms and conditions are patterns of interest for credit scorers [32]. Similarly, visiting a website through a search engine is considered temperate compared to responding to a paid ad [4]. A peak into one's character, which is the key insight sought in psychometric and academic/intellectual data is not an invention of alternative credit scoring. Historically, lending criteria as outlined in the 5C's not only considered a borrower's ability to repay (Capacity, Capital, Collateral), but also whether they were of good character $[2,34]$. The only difference is that the data used to infer character in classical credit analysis was repayment behaviour and patterns [34], while in alternative credit scoring, the data considered is of a much wider range.

One of the strengths of alternative credit scoring is enabling context sensitivity. For instance, rural inhabitants have different sets of data than urban dwellers. For credit scoring smallholder farmers, data such as age, duration in one address, age and family size have been collected [34]. In addition, agricultural data such as farm size, planting and harvesting patterns, crop types and cycles, irrigation and pest control methods as well as yields and sales data have been incorporated in models. These, alongside mobile phone data points, were used to assess credit risk for each farmer [34].

\subsection{Key findings and concerns}

A transformation in credit scoring practice and research has been observed. Although studies on statistical techniques of traditional credit scoring are still steady, there is an increase in research on new machine learning models with advanced capabilities to work with data from new data sources and samples from developing countries [27]. The growth in Big Data both in volume and variety is enabling the development and training of new models [32]. Nontraditional alternative data has shown promise in reliability for credit assessment, as there are various ways of extracting insights that relate to the tried and tested 5C's of credit analysis $[34,36]$. 
While using alternative data to make more people visible has generally been lauded, it has not been without challenge and controversy. Some of the concerns arise from the kind of data utilised to generate credit scores. For instance, the use of public records which include such information as unemployment, evictions and petty crimes lends permanence to transient personal circumstances $[1,19]$. Similar concerns have been raised about psychometric data. An individual's psychometric credit score is reductive and static, therefore detaching the credit risk assessment from people's agency and capacity for reflexivity [5]. Using academic records and geolocation data like zip codes can also reinforce inequalities by entangling personal attributes of the potential loanee with the pseudo biographies that exist about certain demographics and geographic locations $[1,9,25,26]$. Once such data enters the credit scoring algorithm, it encodes the inequality and disenfranchisement, and continues to manifest that reality for those scored using that model $[26,27]$. Most alternative credit scoring tools are proprietary and hence do not present the opportunity for individuals to challenge questionable credit scores [1]. Hence, models built using inaccurate data can go unchecked, even though it is known that implicit biases make their way into algorithms, the results of which are unfair lending practices [32].

Use of data from mobile devices such as contact lists and online friendships has also raised concerns. People's connections in a social network generate a lot of predictive information, but scoring people based on who they are friends with has been deemed unfair and potentially even unethical $[28,30]$. This is closely related to the risk of data privacy and security. There are now massive quantities of data being extracted from mobile devices which includes sensitive information that is a target for cybercriminals [27, 28, 33]. Some of the data can pose real life threats. For instance, geolocation data, call data records and application usage provide near real-time tracking of someone's location and can infer someone's relationships and places of interest such as home and workplace [33]. These risks are disconcerting, particularly in countries where there are knowledge gaps in technology use and data privacy regulations are weak [33].

\section{CONCLUSION, LIMITATIONS AND RECOMMENDATIONS FOR FUTURE RESEARCH}

The spirit behind alternative scoring data has been two-fold. First, it is beneficial for financial institutions to better assess trustworthiness of potential customers especially in instances where datafication in form of credit histories is not available. Secondly, consumers stand a chance of increased access to credit by having alternative data that lenders can use to evaluate them. While current trends in alternative credit scoring serve the achievement of the former objective, the latter may be at risk of being side-lined. The detrimental impact of such neglect are more evident in regions that are still lagging behind the rest of the world in terms of financial inclusion like Sub-Saharan Africa. A vast majority of the population in this region is still unbanked or underbanked [7]. Because of such a low level of financial inclusion, the direction that alternative credit scoring has taken so far may be limiting.

Our analysis reveals that many of the studies that discuss alternative credit scoring focus on technologically enabled and generated data (big data). While such alternative credit scoring options are relevant in the wake of a technologically enabled society, this direction risks excluding those who have already been excluded even further, hence widening the inequality gap in terms of financial inclusion. Many of the data points used in alternative credit scoring models from mobile devices require access to the internet. In developing countries, this is still a challenge, with only $44.4 \%$ internet access compared to $86.7 \%$ in developed countries [12]. [7] found, many alternative credit scoring models only help some of the 'unscored' than the 'invisibles'. To be effective, scoring data must be context-specific [23]. [4] concur by placing an explicit caveat on their findings stating that while digital footprints have worked well for the 'unscorable' in developed economies, the models cannot simply be extrapolated to developing contexts. It therefore becomes paramount for future research to engage with the opportunities for novel alternative scoring models not based on data generated from the internet or from smart devices. This may be especially needful in the changing landscape in developing countries where alternative lending approaches are becoming more popular [9, 22].

With the increasing growth and penetration of mobile technologies in developing countries, mobile phone related data may thus provide novel ways of credit scoring like using airtime credit service metrices [16] or airtime recharge data [22]. However, some of these approaches may be deemed invasive and stakeholders would need to engage with the question on how much mobile consumer information can be shared with lending facilities. One of the challenges of scoring 'invisibles' is lack of financial performance data [5]. There may exist other forms of alternative data that have not yet been utilised for credit scoring for this demographic. For instance, semi-formal and informal financial institutions are popular among the unbanked, with utilisation of as high as 11 to 31 percent in some Sub-Saharan African countries [7]. Activities of semi-formal and informal financial institutions involve saving and borrowing and hence that data is similar to what the 5C's of classical credit scoring seek. For populations at the extreme margins, consideration of data that is relevant to their context is the only lifeline and bridge to financial inclusion.

The geographical distribution of the studies reviewed indicates the need for more empirical research from South America and Sub-Saharan Africa, who alongside South East Asia are home to the majority of the world's 'credit invisibles'. For the financial industry there is, as the CEO of Alpha Credit put it, an opportunity to monetize people whom banks have traditionally denied financial services due to lack of information [22, 40]. This opportunity lies in identifying context-specific non-traditional data, creating and training scoring models to utilise them for the development of appropriate credit and insurance products for the market $[1,39]$.

This paper had several limitations. One of the limitations of the scoping review methodology is that it does not produce highly synthesised results as the aim is to have an overview of existing evidence. Therefore, there are deeper insights from the individual articles reviewed that have not been presented in this paper. Additionally, scoping reviews do not evaluate whether the research that has been carried out by the articles reviewed is of good or poor quality as assessing methodologies and validity of findings for each study is not within the scope of a scoping review [2]. The inclusion 
of only articles published in English may also have excluded other relevant articles published in other languages.

\section{ACKNOWLEDGMENTS}

This work was supported by the Hasso Plattner Institute (HPI) Research School at University of Cape Town.

\section{REFERENCES}

[1] Aitken, R. 2017. "All data is credit data": Constituting the unbanked. Competition and Change. 21, 4 (2017), 274-300. DOI:https://doi.org/10.1177/1024529417712830.

[2] Aji, N.A. and Dhini, A. 2019. Credit scoring through data mining approach: A case study of mortgage loan in Indonesia. 2019 16th International Conference on Service Systems and Service Management, ICSSSM 2019. (2019). DOI:https: //doi.org/10.1109/ICSSSM.2019.8887731.

[3] Arksey, H. and O'Malley, L. 2005. Scoping studies: Towards a methodological framework. International fournal of Social Research Methodology: Theory and Practice. 8, 1 (2005), 19-32. DOI:https://doi.org/10.1080/1364557032000119616.

[4] Berg, T. et al. 2020. On the Rise of FinTechs: Credit Scoring Using Digital Footprints. Review of Financial Studies. 33, 7 (2020), 2845-2897. DOI:https://doi.org/ 10.1093/rfs/hhz099.

[5] Bernards, N. 2019. The poverty of fintech? Psychometrics, credit infrastructures, and the limits of financialization. Review of International Political Economy. 26, 5 (2019), 815-838. DOI:https://doi.org/10.1080/09692290.2019.1597753.

[6] Blumenstock, J. et al. 2015. Predicting poverty and wealth from mobile phone metadata. Science. 350, 6264 (2015), 1073-1076. DOI:https://doi.org/10.1126/ science.aac4420.

[7] Brevoort, K.P. et al. 2016. Credit Invisibles and the Unscored. SSRN Electronic fournal. 18, 2 (2016), 9-34. DOI:https://doi.org/10.2139/ssrn.2743007.

[8] Castell, H. 2018. DECREASING RISK: Innovative credit scoring systems to help farmers. Spore. 187, 2017-2018 (2018), 39.

[9] Citron, D.K., Pasquale, F. 2014. The Scored Society: Due process for automated predictions. Washington Law Review. 89, 1 (2014), 1-33.

[10] De Cnudde, S. et al. 2019. What does your Facebook profile reveal about your creditworthiness? Using alternative data for microfinance. Fournal of the Operational Research Society. 70, 3 (2019), 353-363. DOI:https://doi.org/10.1080/01605682.2018. 1434402.

[11] Demirguc-Kunt, A. et al. 2017. The Global Findex Database 2017.

[12] Djeundje, V.B. et al. 2021. Enhancing credit scoring with alternative data. Expert Systems with Applications. 163, (2021), 113766. DOI:https://doi.org/10.1016/j.eswa. 2020.113766.

[13] Donald, D.C. 2020. Smart Precision Finance for Small Businesses Funding. European Business Organization Law Review. 21, 1 (2020), 199-217. DOI:https: //doi.org/10.1007/s40804-020-00180-1.

[14] Dushimimana, B. et al. 2020. Use of Machine Learning Techniques to Create a Credit Score Model for Airtime Loans. Journal of Risk and Financial Management 13, 8 (2020), 180. DOI:https://doi.org/10.3390/jrfm13080180.

[15] Ebong, J. and Babu, G. 2020. Demand for credit in high-density markets in kampala: Application of digital lending and implication for product innovation. Journal of International Studies. 13, 4 (2020), 295-313. DOI:https://doi.org/10. 14254/2071-8330.2020/13-4/21.

[16] Ghosh, S. and Günther, M.K. 2018. Financial Inclusion Through Public Works Program: Does Gender-Based Violence Make a Difference?

[17] Hudon, M. 2009. Should access to credit be a right? Journal of Business Ethics. 84, 1 (2009), 17-28. DOI:https://doi.org/10.1007/s10551-008-9670-y.

[18] Jagtiani, J. and Lemieux, C. 2019. The roles of alternative data and machine learning in fintech lending: Evidence from the LendingClub consumer platform.

[19] Kear, M. 2017. Playing the credit score game: algorithms, 'positive' data and the personification of financial objects. Economy and Society. 46, 3-4 (2017), 346-368. DOI:https://doi.org/10.1080/03085147.2017.1412642.

[20] Leong, C., Tan, B., Xiao, X., Chian Tan, F., Sun, Y. 2017. Nurturing a FinTech ecosystem: The case of a youth microloan startup in China. International fournal of Information Management. 37, 2017 (2017), 92-97.

[21] Luvizan, S., Nascimento, P., Yu, A. 2016. Big Data for Innovation: The Case of Credit Evaluation Using Mobile Data Analyzed by Innovation Ecosystem Lens.
2016 Proceedings of PICMET '16: Technology Management for Social Innovation (2016), 925-936.

[22] Luvizan, S. et al. 2016. Big Data for Innovation: The Case of Credit Evaluation Using Mobile Data Analyzed by Innovation Ecosystem Lens. 2016 Proceedings of PICMET '16: Technology Management for Social Innovation (2016), 925-936.

[23] Mobile phones are key to economic development. Are women missing out? 2019. https://www.brookings.edu/blog/future-development/2019/04/10/mobilephones-are-key-to-economic-development-are-women-missing-out/. Accessed: 2021-06-17.

[24] Mungai, K. and Bayat, A. 2018. The impact of big data on the South African banking industry. Proceedings of the International Conference on Intellectual Capital, Knowledge Management and Organisational Learning, ICICKM. 2018-Novem, (2018), 225-236.

[25] Nelson, A.A. 2010. Credit scores, race, and residential sorting. fournal of Policy Analysis and Management. 29, 1 (2010), 39-68. DOI:https://doi.org/10.1002/pam. 20478.

[26] Odinet, C.K. 2019. The New Data of Student Debt. Southern California Law Review. 92, 6 (2019), 1617-1692.

[27] Onay, C. and Öztürk, E. 2018. A review of credit scoring research in the age of Big Data. Journal of Financial Regulation and Compliance. 26, 3 (2018), 382-405. DOI:https://doi.org/10.1108/JFRC-06-2017-0054.

[28] Óskarsdóttir, M. et al. 2020. Credit scoring for good: Enhancing financial inclusion with smartphone-based microlending. arXiv. (2020), 1-14.

[29] Óskarsdóttir, M. et al. 2019. The value of big data for credit scoring: Enhancing financial inclusion using mobile phone data and social network analytics. Applied Soft Computing fournal. 74, (2019), 26-39. DOI:https://doi.org/10.1016/j.asoc.2018. 10.004 .

[30] Pedrini, M. et al. 2016. Financial Inclusion and Development: A Cross Country Analysis. Fournal of International Development. 28, (2016), 281-302. DOI:https: //doi.org/10.1002/jid.

[31] Raman, P., Lee, P. 2016. Borrower Beware: Challenges in Providing and Using Consumer Credit. Cityscape. 18, 2 (2016), 3-8.

[32] Rodriguez, L. 2020. All Data Is Not Credit Data: Closing the Gap. 120, 7 (2020), 1843-1884.

[33] Shema, A. 2019. Effective credit scoring using limited mobile phone data. ACM International Conference Proceeding Series. (2019). DOI:https://doi.org/10.1145/ 3287098.3287116

[34] Simumba, N. et al. 2018. Alternative scoring factors using non-financial data for credit decisions in agricultural microfinance. 4th IEEE International Symposium on Systems Engineering, ISSE 2018 - Proceedings. (2018). DOI:https://doi.org/10. 1109/SysEng.2018.8544442.

[35] Smartphone Ownership Is Growing Rapidly Around the World, but Not Always Equally: 2019. https://www.pewresearch.org/global/2019/02/05/smartphoneownership-is-growing-rapidly-around-the-world-but-not-always-equally/. Accessed: 2021-06-17.

[36] Smith, M., Henderson, C. 2018. Beyond thin credit files. Social Science Quarterly. 99, 1 (2018), 24-42.

[37] Smith, M. and Hernderson, C. 2018. Beyond thin credit files. Social Science Quarterly. 99, 1 (2018), 24-42.

[38] Tan, T. et al. 2021. Empowerment of grassroots consumers: A revelatory case of a chinese fintech innovation. Fournal of the Association for Information Systems. 22, 1 (2021), 179-203. DOI:https://doi.org/10.17705/1jais.00658.

[39] Taylor, M. and Wallace-stephens, F. 2019. Work-in-Progress. RSA fournal. 165, 1 (2019), 10-15.

[40] Tazzioli, M. 2019. Refugees' Debit Cards, Subjectivities, and Data Circuits: Financial-Humanitarianism in the Greek Migration Laboratory. International Political Sociology. 13, 4 (2019), 392-408. DOI:https://doi.org/10.1093/ips/olz014.

[41] Thomas, L.C. 2000. A survey of credit and behavioural scoring: Forecasting financial risk of lending to consumers. International fournal of Forecasting. 16, 2 (2000), 149-172. DOI:https://doi.org/10.1016/S0169-2070(00)00034-0.

\section{APPENDIX}

\section{A CHARTING SUMMARY}




\begin{tabular}{|c|c|c|c|c|c|}
\hline Authors & Title & Study Setting & Type of study & Study population & ResearchMethods \\
\hline [4] & $\begin{array}{l}\text { On the Rise of FinTechs: } \\
\text { Credit Scoring Using } \\
\text { Digital Footprints }\end{array}$ & Germany & Empirical & Ecommerce customers & $\begin{array}{l}\text { Case study, } \\
\text { Descriptive } \\
\text { statistics }\end{array}$ \\
\hline [13] & $\begin{array}{l}\text { Smart Precision Finance } \\
\text { for Small Businesses } \\
\text { Funding }\end{array}$ & N/A & Conceptual & None & \\
\hline [26] & $\begin{array}{l}\text { The new data of student } \\
\text { debt }\end{array}$ & United States & Conceptual & None & \\
\hline$[24]$ & $\begin{array}{l}\text { The impact of big data } \\
\text { on the South African } \\
\text { banking industry }\end{array}$ & South Africa & Empirical & $\begin{array}{l}\text { Technology firms and } \\
\text { researchers }\end{array}$ & $\begin{array}{l}\text { Mixed method } \\
\text { study }\end{array}$ \\
\hline$[1]$ & $\begin{array}{l}\text { All data is credit data': } \\
\text { Constituting the } \\
\text { unbanked }\end{array}$ & $\mathrm{N} / \mathrm{A}$ & Conceptual & & \\
\hline [20] & $\begin{array}{l}\text { Nurturing a FinTech } \\
\text { ecosystem: The case of a } \\
\text { youth microloan startup } \\
\text { in China }\end{array}$ & China & Empirical & College students & $\begin{array}{l}\text { Case study } \\
\text { (Qualitative) }\end{array}$ \\
\hline [30] & $\begin{array}{l}\text { Rethinking Microfinance } \\
\text { for Developed Countries }\end{array}$ & $\begin{array}{l}\text { Focus on USA and } \\
\text { European countries }\end{array}$ & Conceptual & & Meta-analysis \\
\hline [9] & $\begin{array}{l}\text { The scored society: Due } \\
\text { process for automated } \\
\text { predictions }\end{array}$ & $\mathrm{N} / \mathrm{A}$ & Conceptual & & Meta-analysis \\
\hline [38] & $\begin{array}{l}\text { Empowerment of } \\
\text { Grassroots Consumers: } \\
\text { A Revelatory Case of a } \\
\text { Chinese Fintech } \\
\text { Innovation }\end{array}$ & China & Empirical & $\begin{array}{l}\text { Money market fund } \\
\text { data }\end{array}$ & $\begin{array}{l}\text { Case study } \\
\text { (Qualitative) }\end{array}$ \\
\hline [32] & $\begin{array}{l}\text { All data is not credit } \\
\text { data: closing the gap } \\
\text { between the fair housing } \\
\text { act and algorithmic } \\
\text { decision-making in the } \\
\text { lending industry }\end{array}$ & $\begin{array}{l}\text { Communities of } \\
\text { Colour in the United } \\
\text { States }\end{array}$ & Conceptual & & \\
\hline [40] & $\begin{array}{l}\text { Refugees' Debit Cards, } \\
\text { Subjectivities, and Data } \\
\text { Circuits: Financial- } \\
\text { Humanitarianism in the } \\
\text { Greek Migration } \\
\text { Laboratory }\end{array}$ & Greece & Empirical & Greece asylum seekers & Case study \\
\hline$[16]$ & $\begin{array}{l}\text { Financial Inclusion } \\
\text { Through Public Works } \\
\text { Program: Does } \\
\text { Gender-Based Violence } \\
\text { Make a Difference? }\end{array}$ & India & Empirical & $\begin{array}{l}\text { women (varied } \\
\text { demographics) }\end{array}$ & Survey \\
\hline [7] & $\begin{array}{l}\text { Credit Invisibles and the } \\
\text { Unscored }\end{array}$ & United States & Empirical & $\begin{array}{l}\text { financial services } \\
\text { consumers }\end{array}$ & $\begin{array}{l}\text { Quantitative } \\
\text { (multivariate } \\
\text { analysis) }\end{array}$ \\
\hline [25] & $\begin{array}{l}\text { Credit Scores, Race, and } \\
\text { Residential Sorting }\end{array}$ & United States & Empirical & $\begin{array}{l}\text { Home mortgage } \\
\text { owners }\end{array}$ & $\begin{array}{l}\text { Case study } \\
\text { Quantitative }\end{array}$ \\
\hline [31] & $\begin{array}{l}\text { Guest Editors' } \\
\text { Introduction: Borrower } \\
\text { Beware: Challenges in } \\
\text { Providing and Using } \\
\text { Consumer Credit }\end{array}$ & $\mathrm{N} / \mathrm{A}$ & $\mathrm{N} / \mathrm{A}$ & $\mathrm{N} / \mathrm{A}$ & $\tilde{\mathrm{N}} / \mathrm{A}$ \\
\hline [39] & Work in Progress & United Kingdom & N/A & $\mathrm{N} / \mathrm{A}$ & $\mathrm{N} / \mathrm{A}$ \\
\hline [12] & $\begin{array}{l}\text { Enhancing credit scoring } \\
\text { with alternative data }\end{array}$ & Multiple & Empirical & Financial data & Experiment \\
\hline
\end{tabular}


[18]
The roles of alternative data and machine learning in fintech lending: Evidence from the Lending club consumer platform The poverty of fintech? Psychometrics, credit infrastructures, and the limits of financialization What does your Facebook profile reveal about your creditworthiness? Using alternative data for microfinance

The value of big data for credit scoring:

Enhancing financial inclusion using mobile phone data and social network analytics Beyond Thin Credit Files Use of Machine Learning Techniques to Create a Credit Score Model for Airtime Loans

Credit scoring through data mining approach: A case study of mortgage

loan in Indonesia Effective credit scoring using limited mobile phone data

Alternative scoring

factors using non-financial data for credit decisions in agricultural microfinance

A review of credit scoring research in the age of Big Data

Credit scoring for good:

Enhancing financial inclusion with smartphone-based microlending Playing the credit score game: algorithms, 'positive' data and the personification of financial objects Big Data for innovation: The case of credit evaluation using mobile data analyzed by innovation ecosystem lens
United States

Empirical

United

States/Zimbabwe

Empirical

Philippines

Empirical

Facebook data

public personal loan data

Statistical Analysis

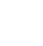

Belgium Empirical

United States

Multiple

Indonesia

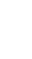

Central African

country

Cambodia

Empirical

Empirical

Empirical

Empirical

Empirical

mobile network

customers

mobile network

customers

Bank generated data set

telecommunication

operator data

Farmers

Developed and

emerging economies

Multiple

Empirical

Empirical

N/A

mobile network customers

Lending circles and non-prime financial subjects

Empirical
Case study

Case study

case study

experiment

Case study:

Predictive and

statistical analytics

Review

Predictive analytics

ethnographic case study

Qualitative Case study 